\title{
Histone H2B Ubiquitylation and Deubiquitylation in Genomic Regulation
}

\author{
N.C.T. EMre AND S.L. BERGER \\ Gene Expression and Regulation Program, The Wistar Institute, Philadelphia, Pennsylvania 19104
}

DNA is organized and packaged in the eukaryotic nucleus via association with octamers of the core histone proteins, comprising two $\mathrm{H} 2 \mathrm{~A} / \mathrm{H} 2 \mathrm{~B}$ dimers bound to a tetramer of $\mathrm{H} 3 / \mathrm{H} 4$. The nucleosome core is formed when 146 base pairs of DNA are wrapped approximately twice around this histone cylinder (Luger 2003). Alterations of the repeating nucleosome structure occur during DNA transactions that include transcription, DNA repair, heterochromatic silencing, and large-scale changes in chromosome compaction during mitosis/apoptosis. The major nucleosome changes are posttranslational covalent modifications of constituent histones and remodeling of the nucleosome. Remodeling encompasses altered nucleosome position and composition, as well as disruption (Flaus and Owen-Hughes 2004). Histone modifications that regulate DNA-based processes include acetylation, phosphorylation, and methylation (Berger 2002). In addition to these relatively small covalent modifications, histones are also modified by much larger ubiquitin (ub) and the related sumo polypeptides (for review, see Jason et al. 2002; Nathan et al. 2003; Zhang 2003).

Several key principles have emerged over a decade of intensive investigation of specific enzymes and their histone substrates. One central paradigm is the notion that addition of and subtraction of a modification are functionally opposed. Thus, histone acetylase enzymes are typically activators of transcription, while histone deacetylase enzymes are generally transcriptional repressors. Another main idea is that acetylation is highly dynamic, being added soon after a transcriptional inducing signal occurs and then being removed following the cessation of the signal (Katan-Khaykovich and Struhl 2002).

A second major theme is the genomic organization of histone modifications, a major dichotomy being that they occur either locally or more globally (Fischle et al. 2003). Thus, during processes that are limited in distance, such as gene-specific transcriptional activation, the scope of the modification may be just one or two nucleosomes. This localization is achieved by sequence-specific DNA-binding proteins, such as transcriptional activators, that recruit the enzymes to the promoter (see, e.g., Brown et al. 2001). More global modifications are accomplished through spreading, which permits the modification and its functional consequence to encompass a broad region, even to the size of chromosomes in the cases of chromosome condensation or X chromosome dosage compensation.
The histone-modifying enzymes are typically constituents of large multimolecular complexes, which include multiple mechanisms through organization into separate protein modules that carry out and regulate specific functions. For example, the transcriptional cofactor and histone acetylation complex SAGA in the yeast Saccharomyces cerevisiae is composed of several modules (Grant et al. 1998). One key function is its ability to associate with DNA-bound activators to provide recruitment for the entire complex. A second function is its enzymatic acetylation activity, which is provided by a catalytic subunit, Gcn5, and substrate specificity is fine-tuned by additional proteins. A third module both positively and negatively regulates TATA-binding protein association with the proximal promoter (Grant et al. 1998; Sterner et al. 1999).

In this paper, we discuss the historical context of histone ubiquitylation and describe recent studies in S. cerevisiae from our laboratory focusing on the role of reversible histone $\mathrm{H} 2 \mathrm{~B}$ ubiquitylation in genomic regulation. Each of the themes touched upon above will be discussed in greater detail. The interesting points that emerge are areas where the role of $\mathrm{H} 2 \mathrm{~B}$ ubiquitylation and deubiquitylation either follow the paradigms that have arisen for other small covalent modifications or, more strikingly, where the role of ubiquitylation diverges from previous general themes.

\section{UBIQUITYLATION AND HISTONES}

Ubiquitin is a 76-residue polypeptide conserved across eukaryotes and, through covalent attachment to substrate proteins, is involved either in proteosome-mediated degradation (Hochstrasser 1996) or in intracellular signaling (Aguilar and Wendland 2003). Ubiquitin is conjugated via an isopeptide bond involving its carboxy-terminal glycine residue through sequential action of three classes of enzymes. These are the E1-activating enzymes and E2-conjugating enzymes working with E3 ligases to transfer ub to specific substrates (Hochstrasser 1996; Wilkinson 2000). The fate of the protein depends on the number of molecules in the ub chain and on which residue within $u b$ is used to form chains. Poly-ub chains longer than four molecules formed through residue Lys48 of ub correlate with proteosomal degradation (Hochstrasser 1996; Wilkinson 2000). However, proteins associated with chains less than four ub molecules, and especially 
with a single (mono) ub, or chains formed through Lys63 linkages are destined for alternate functions. These span diverse processes such as vesicular trafficking, DNA repair, and intracellular localization (Hicke 2001; Aguilar and Wendland 2003). Thus, ub and other ub-like modifications such as sumo are versatile signaling modules that are functionally reminiscent of small molecule protein posttranscriptional modifications like phosphorylation or acetylation.

Most of the histone proteins occur in ub-conjugated forms (Table 1). More than 25 years ago, histone H2A was the first protein shown to be ubiquitylated. Histones constitute the most abundant ub proteins in higher eukaryotes, including $5-15 \%$ of $\mathrm{H} 2 \mathrm{~A}$ and a few percent of H2B (Jason et al. 2002; Zhang 2003; Osley 2004). Ubiquitylation of $\mathrm{H} 3$ may have a role in mammalian spermatogenesis (Chen et al. 1998). The largest subunit of the TFIID coactivator complex, TAF1, monoubiquitylates the linker histone H1, which may have a role in gene activation in Drosophila (Pham and Sauer 2000).

Overall, despite a long history, the detailed mechanisms and physiological significance of histone ubiquitylation has remained relatively poorly characterized until recently. Interestingly, histone ubiquitylation does not cause a dramatic effect on nucleosome compaction in vitro, although its effect on higher-order chromatin formation in vivo remains an open and important question (Jason et al. 2002; Moore et al. 2002). While highly prevalent, ubiquitylation apparently does not mark histones for proteosomal degradation. Regulatory roles of ubiquitylated histones include transcription (as described in detail below), spermatogenesis, and cell cycle (Jason et al. 2002; Zhang 2003; Osley 2004).

\section{HISTONE UBIQUITYLATION SITES AND CROSS-TALK TO HISTONE METHYLATION}

Both sites of histone ubiquitylation and relevant enzymes are currently under investigation (Table 1). Mammalian H2A is ubiquitylated at Lys119 and, while yeast $S$. cerevisiae $\mathrm{H} 2 \mathrm{~A}$ can be ubiquitylated in vitro, it has not been detected in vivo (Robzyk et al. 2000). Lys123 on $\mathrm{H} 2 \mathrm{~B}$ is probably the major yeast histone ubiquitylation site in vivo in rapidly growing cells and is monoubiquitylated by the Rad6/Ubc2 E2 conjugase. Loss of histone $\mathrm{H} 2 \mathrm{~B}$ ubiquitylation causes slow growth in mitotically growing cells and meiotic defects (Robzyk et al. 2000).

Table 1. Histone Ubiquitylation in Saccharomyces cerevisiae and Mammals

\begin{tabular}{llll}
\hline Histone & Site & Process & Enzyme \\
\hline H2A & Lys119 $(\mathrm{m})$ & gene repression & hPRC1L/Ring2 (E3) \\
H2B & Lys120 $(\mathrm{m})$ & gene repression & Mdm2 (E3) \\
& Lys123 $(\mathrm{y})$ & gene activation & Rad6 (E2)/Bre1(E3) \\
H3 & NK $(m)$ & spermatogenesis & NK \\
H4 & NR & NR & NR \\
H1 & NK (m) & gene activation & Taf1(E1/E2) \\
\hline \multicolumn{7}{l}{ (m), mammals; (y), yeast $S$. cerevisiae; NK, not known; NR, not re- } \\
ported. \\
Indirect role in silencing.
\end{tabular}

Bre1, a RING finger protein, is the E3 ligase partner of Rad6 (Hwang et al. 2003; Wood et al. 2003b) involved in histone ubiquitylation (HUB) function. The homologous mammalian residue (Lys120) is also ubiquitylated in vivo in human cells (Jason et al. 2002; Zhang 2003; Minsky and Oren 2004). Ubiquitylation sites have not yet been mapped in cellular H3 and H1.

Aside from roles in DNA repair (Matunis 2002) and meiosis (Yamashita et al. 2004), Rad6-mediated ubiquitylation is implicated in transcription, including inducible gene activation (Kao et al. 2004) and repression (Turner et al. 2002; Carvin and Kladde 2004), as well as telomeric and $H M R$ gene silencing (Huang et al. 1997). The histone H2B ubiquitylating activity of Rad6 is specifically required for these transcriptional activities (Huang et al. 1997; Sun and Allis 2002; Turner et al. 2002; Henry et al. 2003; Hwang et al. 2003; Wood et al. 2003b; Carvin and Kladde 2004; Kao et al. 2004). Rad6 is recruited to gene promoters of constitutive (Wood et al. 2003b) or inducible genes in a Bre1-dependent manner (Kao et al. 2004) coinciding with increased $\mathrm{ubH} 2 \mathrm{~B}$ and preceding mRNA accumulation (Henry et al. 2003; Kao et al. 2004).

The functional outcome of H2B Lys123 ubiquitylation is gene specific. For example, in yeast, transcription of certain genes is activated by ubiquitylation (Henry et al. 2003; Kao et al. 2004), while transcription of other genes is repressed (Turner et al. 2002; Carvin and Kladde 2004). How ubH2B exerts opposing effects on gene transcription is currently not clear. However, the outcome parallels gene-specific positive or negative roles of the SAGA coactivator/acetylase complex itself, and SAGA acts in the same pathways as does ubH2B (Turner et al. 2002; Henry et al. 2003; Kao et al. 2004). In addition, ubiquitylation of mammalian $\mathrm{H} 2 \mathrm{~A}$ and $\mathrm{H} 2 \mathrm{~B}$ has recently been correlated with transcriptional repression rather than activation. First, Mdm2 is known to ubiquitylate p53 to mediate its degradation under normal conditions, that is, in the absence of DNA damage, which activates p53 (Michael and Oren 2003). It now appears that, under normal conditions, Mdm2 associates with p53-inducible genes in a p53-dependent fashion to repress them via mono-ub of H2B at Lys120 and/or Lys125 (Minsky and Oren 2004). It is not clear how repression via p53 recruitment of Mdm2 leading to subsequent H2B ubiquitylation is coordinated with Mdm2-mediated p53 degradation, but there is a precedent in the occurrence of overlapping activation and degradation motifs within transcriptional activators (Muratani and Tansey 2003). A second set of recent studies identified an E3 ligase complex composed of several Polycomb-group proteins that link H2A ubLys 119 to gene repression (Wang et al. 2004) and to the inactive $\mathrm{X}$ chromosome (de Napoles et al. 2004; Fang et al. 2004). Thus, the transcriptional outcome of histone ubiquitylation is not simple and may depend upon many factors, such as the nucleosome structure of the promoter or whether a specific ub site is tied to other modifications, as described below.

In yeast, ubH2B at Lys 123 has an intriguing effect on other histone modifications, which may underlie its transcriptional activation role. Modification of histone H3 with methyl (me) groups on both Lys4 (Dover et al. 
2002; Sun and Allis 2002) and Lys79 (Briggs et al. 2002; $\mathrm{Ng}$ et al. 2002a) depends on ubH2B; that is, either H2B Lys123Arg substitution or RAD6/BRE1 deletion (Hwang et al. 2003; Wood et al. 2003b) abolishes detectable methylation. However, although having a related function, meLys36 in $\mathrm{H} 3$ does not require ubH2B (Briggs et al. 2002; Ng et al. 2002a). Cross-talk between modifications in cis, on the same histone tail, has been characterized in both $\mathrm{H} 3$ and $\mathrm{H} 4$ (for example Lo et al. 2001; see Fischle et al. 2003), caused by increased binding of effector enzymes/proteins (Clements et al. 2003). However, cross-talk in trans, among modifications residing on different molecules (i.e., ubH2B and meH3) is unique. Trans-tail cross-talk may actually be direct since ubH2B and meLys4 may coexist on the same or neighboring nucleosomes (Sun and Allis 2002). Although the molecular mechanism creating the linkage is not understood (Henry and Berger 2002), methylation may be the functional readout of ubiquitylation in transcriptional activation, since there are strong parallels between ubH2B and meH3. For example, similar to ubH2B, Dot1-dependent meLys79 and Set1-dependent meLys4 are implicated in silencing (Nislow et al. 1997; Singer et al. 1998; Briggs et al. 2001; Bryk et al. 2002; Feng et al. 2002; Krogan et al. 2002; Ng et al. 2002b; van Leeuwen et al. 2002), activated gene transcription (Noma and Grewal 2002; Santos-Rosa et al. 2002), and repression (Carvin and Kladde 2004). These data strongly suggest that $\mathrm{ubH} 2 \mathrm{~B}$ acts in the same pathway with meLys4 and meLys79 in transcription.

Recent studies have identified two potential mechanisms that link ubiquitylation and methylation in this trans-histone pathway. First, components of the Paf1 transcriptional elongation complex are implicated in the cross-talk (Gerber and Shilatifard 2003). The Pafl complex is associated primarily with elongating forms of RNA polymerase II (RNAPII), and thus Paf1 mutations exhibit defects in transcriptional elongation (Shilatifard 2004). Interestingly, mutations in the Pafl complex also have very low levels of ubH2B, meLys4, and meLys79 and are defective in silencing. Indeed, Rad6/Bre1 and Set1 are all associated with early elongating RNAPII and loss of Paf1 leads to loss of the histone modification enzymes (Krogan et al. 2003a; Ng et al. 2003a,b; Wood et al. 2003a). In this setting, the Pafl complex may provide a "platform" for interaction of the modification enzymes with RNAPII (Gerber and Shilatifard 2003). A second fascinating connection between histone ubiquitylation and methylation is related to previous observations that nondegradative portions of the proteosome are associated with gene promoters (Gonzalez et al. 2002). ATPase components of the proteosome were recently shown to be required for efficient meLys4 and meLys79, and ubH2B is required for recruitment of the ATPases (Ezhkova and Tansey 2004). ATPase mutations, similar to ubiquitylation and methylation deficiencies, cause both silencing and gene activation defects. It is possible that the subproteosomal module may alter the nucleosomal template to mediate methylation of histone H3. Thus, although the precise steps and physical associations are not yet known, there are several potential direct recruitment steps in this intricate pathway.

\section{H2B DEUBIQUITYLATION BY Ubp8 IS INVOLVED IN TRANSCRIPTION OF SAGA/Gcn5-DEPENDENT GENES}

Our recent data indicate that $\mathrm{H} 2 \mathrm{~B}$ deubiquitylation also regulates transcriptional activation. Many posttranslational modifications of proteins are reversed by specific enzymes. For example, HDACs (histone deacetylases) remove acetyl groups from histones. In most cases, removal results in the opposing function, e.g., histone acetyl transferases (HATs) activate genes and HDACs repress them (Kurdistani and Grunstein 2003). Ubiquitylation is similar in that ub conjugation is countered by the action of deubiquitylating enzymes (DUBs; for review, see Wilkinson 1997, 2000; Soboleva and Baker 2004). DUBs are thiol proteases that cleave the isopeptide bond at the carboxy-terminal-most Gly76 residue of ub, either removing ub from the substrate or processing the poly-ub chain. DUBs have been traditionally classified into two families, although there may be additional families (Soboleva and Baker 2004). One family, called ub carboxy-terminal hydrolases (UCHs), cleave ub from small adducts, such as amides or short peptides. The second family comprises the ub-specific proteases (abbreviated as UBPs for yeast proteins and as USPs for mammalian proteins). These are composed of 16 putative members in yeast and more than 80 in humans, making this family the largest in all ubiquitylation-related processes. The defining characteristic of UBPs is the presence of conserved domains, called the Cys-box and His-box, which are involved in formation of a "catalytic triad" for proteolytic cleavage and are reminiscent of the papain family of cysteine proteases (Wilkinson 1997; Hu et al. 2002, and references therein). UBPs mainly differ by insertions between the catalytic boxes or having divergent amino- or carboxy-terminal extensions, all of which may be involved in substrate selectivity (Wilkinson 1997; Soboleva and Baker 2004). DUBs are involved in several biological processes, such as cell growth, differentiation, immune function, and memory consolidation; DUB mutants are implicated in disease states, such as cancer (for review, see Wilkinson 1997; Chung and Baek 1999; Soboleva and Baker 2004). Nevertheless, other than in proteosomal degradation, little was known about deubiquitylation until recently, especially with regard to mono ub signaling.

One revealing finding was that Ubp8, a putative ub hydrolase, is a novel component of the SAGA coactivator complex (Sanders et al. 2002). Because we linked H2B ubiquitylation with SAGA complex-dependent gene activity (Henry et al. 2003; Kao et al. 2004), we investigated whether Ubp8-mediated H2B deubiquitylation occurs in the context of SAGA (reviewed in Wyce et al. 2004). We and others found that Ubp8 is a stable and stoichiometric subunit of SAGA and has a role in H2B deubiquitylation in vitro and in vivo (Henry et al. 2003; Daniel et al. 2004). Ubp8 is recruited to the SAGA-dependent GAL1-10 gene promoter upon induction (Henry et al. 2003; Daniel et al. 2004), coincident with the Gen5 HAT subunit of SAGA, leading to decreased ubH2B levels (Henry et al. 2003). As discussed above, antagonistic actions of histone-mod- 
ifying enzymes generally result in opposite functional outcomes. However, we found that both ubiquitylation and deubiquitylation of $\mathrm{H} 2 \mathrm{~B}$ are required for the proper activation of SAGA-dependent genes (Henry et al. 2003). We examined the basis of this unusual requirement and found that the absence of $\mathrm{H} 2 \mathrm{~B}$ ubiquitylation compared to the absence of $\mathrm{H} 2 \mathrm{~B}$ deubiquitylation exhibits different defects in meH3. Targeted H3 Lys4 trimethylation occurs at the $5^{\prime}$ end of the ORF early during transcript elongation (Santos-Rosa et al. 2002; Ng et al. 2003b), while H3 Lys36 methylation occurs primarily later during transcript elongation (Krogan et al. 2003b; Xiao et al. 2003). As described above, ubH2B is required for H3 Lys4 and Lys79 methylation, but is not required for H3 Lys36 methylation. We found that ubiquitylation is required for meLys 4 while deubiquitylation is required for meLys 36 , leading to a proposal that sequential ubiquitylation and deubiquitylation of $\mathrm{H} 2 \mathrm{~B}$ establishes the correct balance among H3 methylations required for proper gene activation (Fig. 1) (Henry et al. 2003; Wyce et al. 2004).

The catalytic domain of Ubp8 is similar to other putative UBPs. Indeed, we found that yeast Ubp10 also deubiquitylates $\mathrm{H} 2 \mathrm{~B}$, but has a distinct genomic function and localization (see below). It appears that correct targeting is crucial for distinct roles of catalytically indistinguishable (at least with regard to H2B) Ubp8 or Ubp10. We in- vestigated the basis for Ubp8 targeting and noted an amino-terminal cysteine/histidine-rich region. This region is predicted to bind zinc, forming a type of zinc finger called ZnF_UBP (Pfam domain ID\# PF02148; Bateman et al. 2004). ZnF_UBP is also present in other UBPs and in mHDAC6 (a histone deacetylase), where, interestingly, it is involved in ub binding (Seigneurin-Berny et al. 2001; Hook et al. 2002). Since zinc fingers are known to be versatile modules for DNA and protein interaction (Laity et al. 2001), we tested a possible role in interaction with SAGA using a panel of deletion and substitution mutants. We found that the Ubp $8 \mathrm{ZnF}$ is important for association of Ubp8 with SAGA and for Ubp8's deubiquitylating activity in vivo (i.e., Ubp 8 must be associated with SAGA for its enzymatic activity). In contrast, mutations in the catalytic domain reduce enzyme activity on ubH2B, as expected, but not SAGA association (Ingvarsdottir et al. 2005). Furthermore, when combined with deletion of $G C N 5$, either catalytic or zinc finger mutants are defective in pathways requiring SAGA, suggesting that Ubp8 exerts its effects through histone $\mathrm{H} 2 \mathrm{~B}$ deubiquitylation and as a part of SAGA complex (Ingvarsdottir et al. 2005).

We and others recently identified a second novel component of SAGA, called Sgf1 1 ( $\underline{\text { SAG }}$ A-associated factor 11 kD) (Lee et al. 2004; Powell et al. 2004; Ingvarsdottir

A
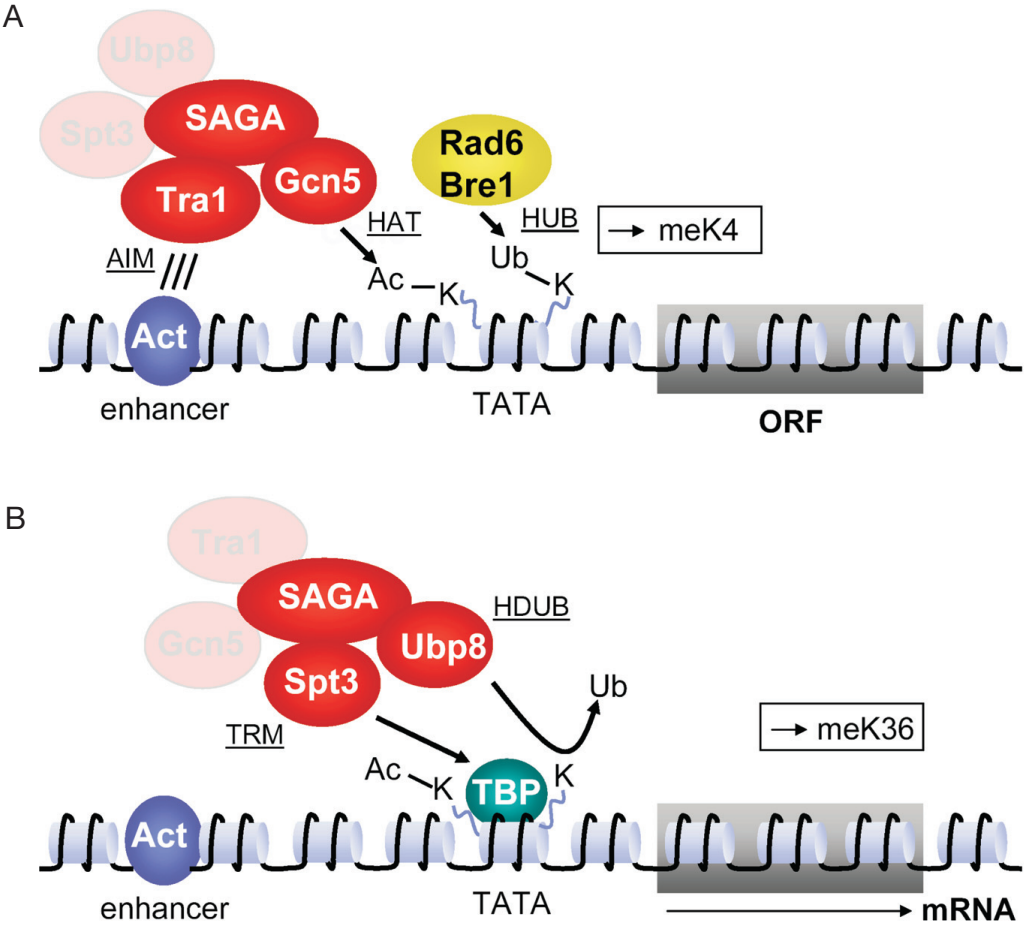

Figure 1. Model of SAGA modularity during transcriptional gene activation. SAGA is depicted in red, with one representative component from each module highlighted (i.e., Gen5 of the HAT module; Tra1 of the activator interaction module [AIM]; Spt3 of the TBP [TATA-binding protein] regulation module [TRM]; Ubp8 of the histone deubiquitylase [HDUB] module). The roles of targeted action of SAGA in controlling transcriptional initiation and the transition from initiation to elongation are represented in two panels. (A) Recruitment of SAGA through AIM by a DNA-bound activator, and consequent acetylation of histones by the HAT module works in parallel with Rad6/Bre1-dependent histone H2B ubiquitylation and consequent Set1-dependent histone H3 methylation at Lys4. $(B)$ This leads to preinitiation complex formation at the promoter through recruitment of TBP by the TRM. The transition to efficient transcriptional elongation depends on HDUB-mediated histone deubiquitylation and consequent Set2-dependent histone H3 Lys36 methylation. SAGA functions in these two stages need not be mutually exclusive, such as a possible requirement of the HAT module in the later elongation stages. 
et al. 2005). Interestingly, Sgf1 1 is important for association of Ubp8 with SAGA (Powell et al. 2004; Ingvarsdottir et al. 2005; Lee et al. 2005) and for histone H2B deubiquitylation (Ingvarsdottir et al. 2005). Ubp8 interacts with Sgf11 in vivo through the Ubp8 ZnF (Ingvarsdottir et al. 2005). We have found that the functions of Ubp8 and Sgf11 are related and separable from other components of SAGA, such as Gcn5/Ada2/Ada3 (HAT module) or $\mathrm{Spt} 3 / \mathrm{Spt} 7$ /Spt8 (TBP regulatory module, TRM). In particular, the profiles of UBP 8 and SGF11 deletions are remarkably similar in global gene expression analyses and large-scale synthetic genetic interactions (Ingvarsdottir et al. 2005). These results indicate that Ubp8 and Sgf11 represent a new functional module within SAGA ("histone deubiquitylase" [HDUB] module) involved in gene regulation through $\mathrm{H} 2 \mathrm{~B}$ deubiquitylation and consistent with the modular construction of SAGA (Grant et al. 1998). Whether Ubp8 and Sgf1 1 represent a separable, physical module remains to be established.

In summary, SAGA possesses a histone deubiquitylation module in addition to a histone acetylation module and these have quite distinct functions within the complex. Both enzymatic activities are required for SAGA's role in transcriptional activation of certain genes. One novel aspect to dynamic histone ubiquitylation is that it appears to increase early in gene activity and then, in contrast to histone acetylation, is rapidly cleaved. The failure to remove ub blocks the sequence of steps that occurs during gene activation and results in the failure to progress from H3 Lys4 methylation to H3 Lys36 methylation (Henry et al. 2003). Finally, Ubp8 is targeted to genes in a local fashion, through zinc finger domain and Sgf11-mediated association with SAGA (Ingvarsdottir et al. 2005), which is recruited to promoters through activator interaction with its Tral subunit (Brown et al. 2001).

\section{SILENCING AND Ubp10 AS A HISTONE H2B DEUBIQUITYLATING ENZYME IMPLICATED IN SILENCING}

In contrast to activator-mediated local recruitment of chromatin modification complexes to regulate transcription, other DNA-templated processes require broader recruitment, to either certain regions of the genome or even to whole chromosomes. We have identified a second H2B deubiquitylating enzyme, Ubp10, that indeed has a broader role than Ubp8, helping to maintain quiescence of certain regions within the yeast genome (Emre et al. 2005). These quiescent regions are similar in some respects to densely staining, late replicating heterochromatic regions of higher eukaryotic genomes. The chromatin within these regions tends to repress RNA polymerase II transcription, a phenomenon called "heterochromatic gene silencing." For example, transgenes inserted into silenced loci are repressed in a gene-nonspecific manner. In yeast these regions famously include telomeres, silent mating type loci (HMR and $H M L)$, and the rDNA locus (Huang 2002; Rusche et al. 2003).

Covalent modifications of histone tails are involved in silencing (Grunstein 1997). Telomeric silencing, also referred to as telomere position effect (TPE) in budding yeast (Gottschling et al. 1990), requires the SIR (Silent Information Regulatory) complex, composed of Sir3, Sir4, and the Sir2 HDAC. The Sir complex is recruited to telomere tips through interactions with sequence-specific DNA-binding proteins such as Rap1. Sir proteins bind to hypoacetylated tails and spread inward from telomeres as Sir2 deacetylates histone tails of neighboring nucleosomes (Huang 2002; Rusche et al. 2003; Moazed et al. 2004). Similar mechanisms act at the silent mating loci. Recent studies suggest spreading is counteracted at boundary regions by acetylation through the HAT Sas2 (Kimura et al. 2002; Suka et al. 2002) and by the presence of the histone variant H2A.Z (Meneghini et al. 2003) and other proteins, including bromodomain-containing Bdf1 (Ladurner et al. 2003) at boundary regions.

Methylation of lysine residues in histone tails has also been implicated in heterochromatin related silencing both in budding yeast (van Leeuwen and Gottschling 2002; Ng et al. 2003c; Santos-Rosa et al. 2004) and in other eukaryotes, however with notable differences: H3 Lys9 and Lys27 methylation silence through direct recruitment of heterochromatic chromodomain-containing proteins HP1 and Polycomb (Pc), respectively (Grewal and Moazed 2003). On the other hand, yeast apparently lack repressive histone methylation and homologs of the binding partners. Instead H3 Lys4 and Lys79 methylation are required, but indirectly, because these modifications are found primarily in active chromatin and may provide a relatively stable (compared to acetylation) memory mark for genes per se (Bernstein et al. 2002; Ng et al. 2003b). Furthermore, ubH2B has also been implicated in silencing, as described above, in part probably because of its requirement for H3 Lys4 and Lys 79 methylation.

Our study of Ubp8 in histone deubiquitylation during gene activation prompted us to investigate whether other $\mathrm{ub}$ proteases in yeast may target $\mathrm{H} 2 \mathrm{~B}$ in transcriptional regulation. We considered two candidates in regulating gene silencing, Ubp3 and Ubp10 (Moazed and Johnson 1996; Singer et al. 1998). We found that the level of $\mathrm{ubH} 2 \mathrm{~B}$ is increased in a strain deleted for $U B P 10$, similar to the effect of $U B P 8$ deletion, but not in the absence of UBP3 (Henry et al. 2003; Emre et al. 2005). We confirmed that $\mathrm{H} 2 \mathrm{~B}$ is a substrate for Ubp10 in vitro using purified recombinant $\mathrm{Ubp} 10$, suggesting that $\mathrm{ubH} 2 \mathrm{~B}$ is a direct target of Ubp10. In addition, ChIP assays demonstrate that deletion of UBP10 leads to increased $\mathrm{ubH} 2 \mathrm{~B}$, specifically at a telomere proximal region, and Ubp 10 is present at the affected regions. Further, in the absence of Ubp10, expression of a normally strongly silenced gene within this affected region is increased (Emre et al. 2005). These data provide a clear model that Ubp10 is directed to telomere proximal regions to maintain low ubiquitylation leading to low gene expression.

We further investigated molecular mechanisms of Ubp10 in silencing. We hypothesized that histone $\mathrm{H} 3$ methylation levels may be increased and Sir protein localization may be lowered at the telomere upon loss of Ubp10. The reasoning followed from evidence that ubH2B is required for H3 Lys4 (Dover et al. 2002; Sun and Allis 2002) and Lys79 (Briggs et al. 2002; Ng et al. 2002a) methylation in euchromatic regions of the 
genome, and especially in open reading frames (ORFs). Mutations that prevent these methylations cause silencing defects (see above), likely because of Sir protein relocalization from silenced to active regions (van Leeuwen and Gottschling 2002). These observations and earlier studies on Sir complex binding to undermodified histones (Carmen et al. 2002) prompted a model to explain the relationship between global histone modifications and silencing (van Leeuwen and Gottschling 2002): Lack of global modifications on histone tails (such as lack of H3 Lys4 or Lys79 methylation, or lysine acetylation) lead to loss of Sir proteins (whose levels are limited in the cell) away from silenced regions, causing silencing defects. These observations and models led us to test whether the increase in $\mathrm{ubH} 2 \mathrm{~B}$ in the absence of Ubp10 leads to an increase in $\mathrm{meH} 3$. We found that overexpression of Ubp 10 leads to loss of global ubH2B and loss of $\mathrm{H} 3$ meLys4/meLys79 as well, although certain other unrelated modifications were not altered. Chromatin immunoprecipitation (ChIP) analysis showed that loss of Ubp10 also causes increased H3 meLys4 and meLys 79 methylations close to the telomere but not at internal, active regions (Emre et al. 2005). Interestingly, loss of
Ubp10 lowers the level of Sir2 association at the telomere and, reciprocally, loss of Sir2 lowers Ubp10. Further, using ChIP analysis we detected Ubp10 association with rDNA regions where Ubp10 deletion also leads to increased H3 methylation (Emre et al. 2005).

These observations suggest the following model (Fig. 2): Ubp 10 is preferentially associated with and deubiquitylates H2B within silent chromatin, contributing to low methylation and helping to promote Sir association. Deletion of UBP10 causes an increase in $\mathrm{ubH} 2 \mathrm{~B}$, leading, in turn, to increased meH3; methylation of histone $\mathrm{H} 3$ is unfavorable for Sir protein association with the chromatin (van Leeuwen and Gottschling 2002; Ng et al. 2003c; Santos-Rosa et al. 2004), and presumably ubiquitylation is also incompatible with Sir binding. Decreased Sir2 binding in turn leads to decreased Ubp10 binding. Thus, there is a feedback loop between the HDAC and HDUB to maintain low modifications and silencing. On the other hand, overexpression of Ubp10 leads to global deubiquitylation of histone H2B (and global hypomethylation of H3 Lys4 and Lys79), which results in promiscuous binding of Sir proteins to normally active chromatin, causing the limited pools of Sirs to escape from silenced regions.

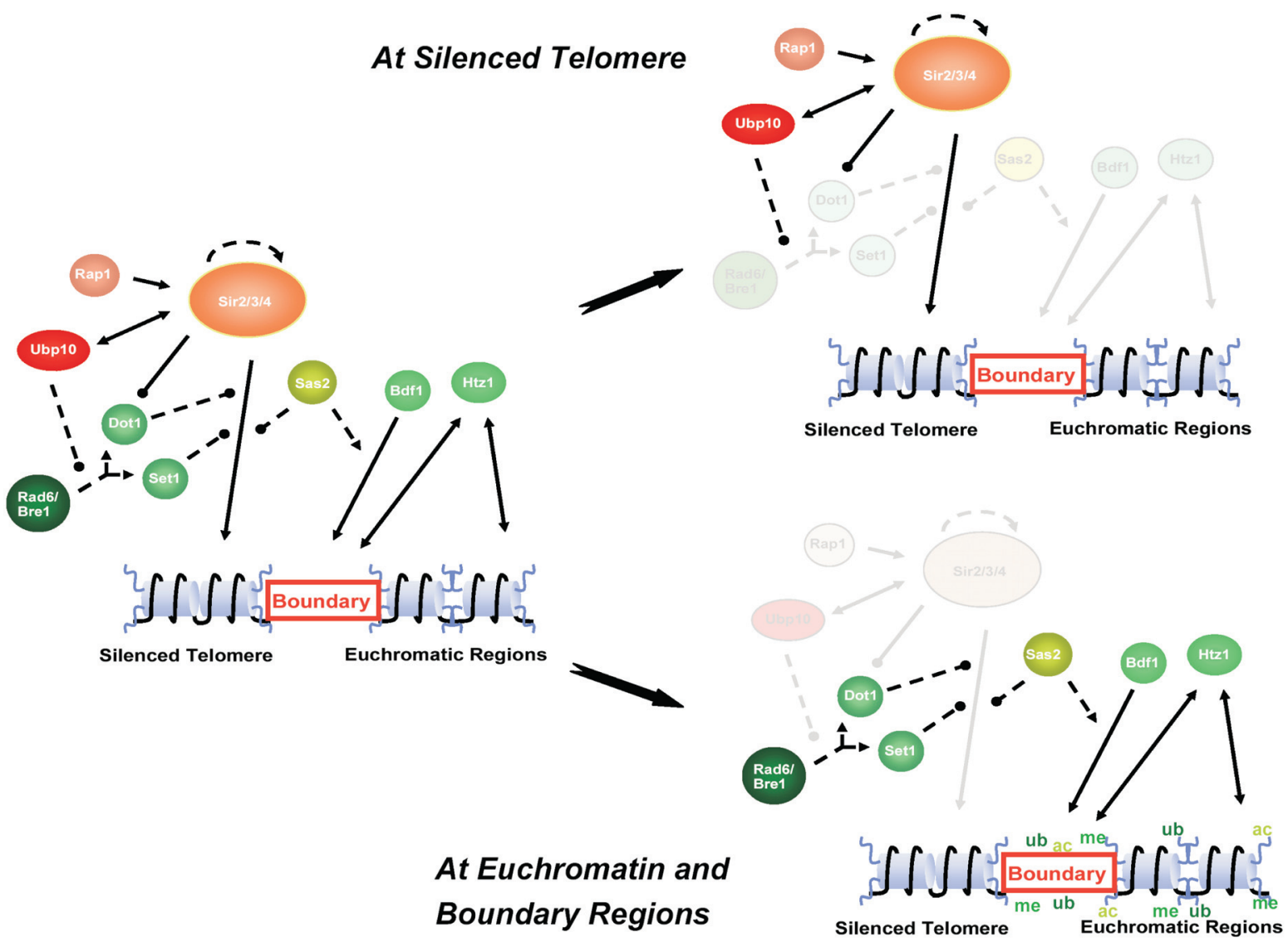

Figure 2. Model for yeast telomeric silencing incorporating the major factors known to act through histone modifications. Silencing Sir complex (Sir2/3/4), and factors that limit silencing in yeast (e.g., Htz1 and Bdf1) are shown competing for chromatin binding (left). Solid lines denote molecular interactions (with arrowheads), or inhibition of molecular interactions (with spheres). Dashed lines denote enzymatic activities on histones, either promoting a step in the pathway (with arrowheads) or inhibiting (with spheres). Typical outcomes are silencing at the telomere-proximal regions (top right), or protection from silencing at the euchromatin boundary (bottom right). Only relevant factors are drawn (not to scale). 


\section{Ubp8 VERSUS Ubp10: SAME HISTONE SUBSTRATE, DIFFERENT GENOMIC PROCESSES}

Our characterization of Ubp8 and Ubp10 as histone $\mathrm{H} 2 \mathrm{~B}$ deubiquitylating enzymes raised the possibility that there might be an overlap or redundancy in their functions, in spite of the fact that they were discovered in very different functional contexts (Singer et al. 1998; Sanders et al. 2002; Henry et al. 2003). However, numerous observations (Table 2) suggest that Ubp10 and Ubp8 engage in nonoverlapping, distinct molecular processes, i.e., regional silencing and locus-specific activated gene transcription, respectively. First, loss of both Ubp10 and Ubp8 exhibit far higher levels of ubH2B compared to loss of either single enzyme, consistent with each enzyme targeting a separate subpopulation of $\mathrm{ubH} 2 \mathrm{~B}$. Second, while Ubp8 and Gcn5 work cooperatively to activate genes that require SAGA function (Henry et al. 2003), Ubp10 does not display cooperativity with Gcn5 (Emre et al. 2005). Third, Ubp8 does not function similarly to Ubp10 in regulation of silencing: Ubp8 is not preferentially localized to telomere-proximal regions; deletion of Ubp8 does not increase telomere proximal levels of $\mathrm{ubH} 2 \mathrm{~B}, \mathrm{meH} 3$, or gene expression (Emre et al. 2005). Finally, deletion of Ubp10, but not Ubp8, shows genetic interactions with the components of SWR-C, the nucleosome remodeling complex implicated in the disposition of silencing-related histone variant H2A.Z (reviewed in Korber and Horz 2004). Taken together, these data suggest that Ubp10 and Ubp8 are involved in distinct molecular processes, although they both target histone H2B for deubiquitylation.

\section{SUMMARY AND PERSPECTIVES}

Our observations considered along with recent studies from other laboratories indicate that histone H2B ubiquitylation and deubiquitylation, similar to acetylation and deacetylation, regulate two distinct aspects of transcriptional regulation: gene-specific expression (Fig. 1) and heterochromatic-like silencing in yeast (Fig. 2). Thus, in the first case, transcription is regulated by localized, dynamic ubiquitylation and deubiquitylation. $\mathrm{H} 2 \mathrm{~B}$ ubiquitylation is catalyzed by recruitment of the E2/E3 partners
Rad6/Bre1, which, in a trans-tail relationship, triggers H3 methylation of Lys4 and Lys79. However, in apparent contrast to the typical situation, such as with acetylation/deacetylation causing activation/repression, H2B deubiquitylation is also required for productive transcription (Henry et al. 2003). This is catalyzed by activator-dependent recruitment of SAGA-associated $\mathrm{ub}$ protease Ubp8, which causes a transition of the predominant $\mathrm{H} 3$ methylation from Lys4/Lys79 to Lys36. Ubp8 is associated with Sgf1 1 as a functional module within SAGA that is mechanistically distinct from the acetylase Gcn5/ Ada2/Ada3 or TBP-regulatory Spt3/Spt7/Spt 8 modules (Ingvarsdottir et al. 2005).

Certain larger regions of the yeast genome, such as telomeres, are maintained in special "gene silencing" conformations, probably to prevent recombination and promote genome stability (Huang 2002; Rusche et al. 2003). It appears that histone acetylation/ubiquitylation, and thus $\mathrm{H} 3$ methylation, are constitutively low in these regions relative to transcriptionally poised ORF-rich euchromatin, which in contrast appears to bear constitutive H3 methylation to mark genes. Our data suggest that the deacetylase Sir2 and the deubiquitylase Ubp10 cooperatively maintain the hypomodified state through binding/spreading along the chromatin (Emre et al. 2005). Although the Sir complex is initially recruited by DNA sequence-specific binding proteins, the binding thereafter is less specific, with preference to undermodified histone tails. The complex is believed to extend along the chromatin fiber until a boundary element is reached, which is composed of H2A.Z, tRNA genes, and other marks. Sir binding, in turn, directly or indirectly recruits Ubp10 to the silenced regions. As previously suggested (Ng et al. 2003c), positive feedback loops may contribute to the epigenetic nature of telomere position effect, which is similar to position effect variegation (PEV) where distinct quasi-stable states, such as transcriptionally active or repressed telomeres, can be maintained for many generations among genetically identical cells.

Some general questions arise in considering the roles of histone ubiquitylation and deubiquitylation. One issue is whether there is a general role for ubiquitylation. In yeast, ubiquitylation is transcriptionally activating, whereas, in higher eukaryotes, it has both activating and

Table 2. Comparison of Ubp8 and Ubp10 Functions

\begin{tabular}{|c|c|c|}
\hline Function & Ubp8 & Ubp10 \\
\hline \multicolumn{3}{|l|}{ HDUB activity } \\
\hline in vitro & yes & yes \\
\hline in vivo & yes & yes \\
\hline $\begin{array}{l}\text { HDUB genomic targets and } \\
\text { localization }\end{array}$ & SAGA-inducible gene promoters & $\begin{array}{l}\text { silenced regions ( } T E L, \\
H M L / R, \text { rDNA) }\end{array}$ \\
\hline Recruitment & DNA-bound activators ${ }^{\mathrm{a}}$ & Sir complex \\
\hline Effect on silenced genes & no & yes \\
\hline Effect on gene induction & yes & $\mathrm{no}^{\mathrm{b}}$ \\
\hline Effect on $\mathrm{H} 3$ methylation & $\begin{array}{l}\text { regulatory: } \\
\text { lowers Lys } 4^{c} \\
\text { raises Lys36 }\end{array}$ & lowers Lys4/Lys79 \\
\hline
\end{tabular}


repressing functions, as described above. How are these diverse outcomes achieved? One possibility is that, similar to methylation and acetylation, various effector proteins bind to ubiquitylated histones at different promoters, and these effectors lead to different functional readouts. One interesting example is that $\mathrm{ubH} 2 \mathrm{~A}$ may bind the linker histone $\mathrm{H} 1$ more strongly than $\mathrm{H} 2 \mathrm{~A}$ resulting in repression through chromatin compaction (Jason et al. 2004). A second model is suggested by the ubiquitylation/methylation trans-tail connection that exists in yeast. Similar ub/me patterns may exist in higher eukaryotes, but where methylation is both activating (e.g., H3 meLys4) and repressing (e.g., H3 meLys9), leading to dramatically divergent final functional readouts. However, as yet there is no reported evidence for a ubiquitylation/methylation trans-tail pattern outside of yeast $(S$. cerevisiae and Schizosaccharomyces pombe [Roguev et al. 2003]). A third hypothesisis is that ubiquitylation leads to alterations in the nucleosomal template itself and, depending on the nucleosome structure at the promoter, opens or compacts the chromatin. Finally, histone depletion has been detected around genes in yeast (Boeger et al. 2004; Korber et al. 2004; Schwabish and Struhl 2004). Ubiquitylation could lead to histone depletion through more conventional proteosomal degradation, which would activate or repress depending on subsequent binding of new regulatory proteins.

Considering both the significance of the reversibility concept in protein posttranslational modifications and the large number of putative deubiquitylating enzymes, it is not surprising that histone deubiquitylation is emerging as a means to control transcriptional processes, such as gene activation and silencing. However, it is not clear whether histone deubiquitylation has a general role during transcription, as appears to be true for Ubp8 in yeast, to serve as a gatekeeper or checkpoint. Our data suggest that deubiquitylation primes the elongation process to proceed to the next step in a series. Thus, early elongation (characterized by H3 Lys4 methylation) requires ubiquitylation; the switch to later elongation (characterized by H3 Lys36 methylation) requires deubiquitylation. Many questions arise here: What is the mechanism by which ubiquitylation blocks the elongation progress? Does ubiquitylation serve a similar checkpoint function during transcriptional repression? It is also completely unknown whether higher eukaryotes have a similar system at authentic heterochromatin as Ubp10's role in heterochromatin-like silencing in yeast in maintaining constitutively low ubiquitylation/methylation.

Histone ubiquitylation has a role in processes beyond transcription and silencing. The $\mathrm{ubH} 2 \mathrm{~B}-\mathrm{meH} 3$ trans-tail modification pathway is involved in DNA double strand break (DSB) formation and repair. Rad6-dependent histone $\mathrm{H} 2 \mathrm{~B}$ ubiquitylation is important for meiosis (Robzyk et al. 2000), possibly because of its role in DSBs (Yamashita et al. 2004). Similarly, Set1 (Sollier et al. 2004) and Dot1 (San-Segundo and Roeder 2000; Game et al. 2005) function during meiosis and/or DSB formation and, in mammalian cells, meLys 79 may provide a recognition mark for binding of DNA damage sensor proteins to DSBs (Huyen et al. 2004). It will be interesting to learn whether histone deubiquitylating enzymes also regulate these processes.

Thus, histone ubiquitylation and deubiquitylation have emerged as key regulatory signals in eukaryotes during transcription, silencing, and beyond. Similar to histone acetylation, ubiquitylation largely correlates with open, active chromatin in yeast and thus is involved in transcription and DNA repair and is absent from heterochromatin-like regions. In contrast to the role of histone acetylation in transcription, both adding and removing $\mathrm{ub}$ is required for productive RNA synthesis in yeast. Understanding the function of transcriptional repressive ubiquitylation in higher eukaryotes may provide key insight into possible general mechanisms.

\section{ACKNOWLEDGMENTS}

We thank K. Ingvarsdottir, A. Wyce, K.W. Henry, A. Wood, N.J. Krogan, K. Li, R. Marmorstein, J.F. Greenblatt, and A. Shilatifard for their contributions to the studies on ubiquitin proteases that were in press at the time of this review. These studies are supported by grants from the National Institutes of Health and the National Science Foundation to S.L.B.

\section{REFERENCES}

Aguilar R.C. and Wendland B. 2003. Ubiquitin: Not just for proteasomes anymore. Curr. Opin. Cell Biol. 15: 184.

Bateman A., Coin L., Durbin R., Finn R.D., Hollich V., Griffiths-Jones S., Khanna A., Marshall M., Moxon S., Sonnhammer E.L., Studholme D.J., Yeats C., and Eddy S.R. 2004. The Pfam protein families database. Nucleic Acids Res. 32: database issue D138.

Berger S.L. 2002. Histone modifications in transcriptional regulation. Curr. Opin. Genet. Dev. 12: 142.

Bernstein B.E., Humphrey E.L., Erlich R.L., Schneider R., Bouman P., Liu J.S., Kouzarides T., and Schreiber S.L. 2002. Methylation of histone H3 Lys 4 in coding regions of active genes. Proc. Natl. Acad. Sci. 99: 8695 .

Boeger H., Griesenbeck J., Strattan J.S., and Kornberg R.D. 2004. Removal of promoter nucleosomes by disassembly rather than sliding in vivo. Mol. Cell 14: 667.

Briggs S.D., Bryk M., Strahl B.D., Cheung W.L., Davie J.K., Dent S.Y., Winston F., and Allis C.D. 2001. Histone H3 lysine 4 methylation is mediated by Set 1 and required for cell growth and rDNA silencing in Saccharomyces cerevisiae. Genes Dev. 15: 3286.

Briggs S.D., Xiao T., Sun Z.W., Caldwell J.A., Shabanowitz J., Hunt D.F., Allis C.D., and Strahl B.D. 2002. Gene silencing: Trans-histone regulatory pathway in chromatin. Nature 418: 498.

Brown C.E., Howe L., Sousa K., Alley S.C., Carrozza M.J., Tan S., and Workman J.L. 2001. Recruitment of HAT complexes by direct activator interactions with the ATM-related Tra1 subunit. Science 292: 2333.

Bryk M., Briggs S.D., Strahl B.D., Curcio M.J., Allis C.D., and Winston F. 2002. Evidence that Set1, a factor required for methylation of histone $\mathrm{H} 3$, regulates rDNA silencing in $\mathrm{S}$. cerevisiae by a Sir2-independent mechanism. Curr. Biol. 12: 165 .

Carmen A.A., Milne L., and Grunstein M. 2002. Acetylation of the yeast histone $\mathrm{H} 4 \mathrm{~N}$ terminus regulates its binding to heterochromatin protein SIR3. J. Biol. Chem. 277: 4778.

Carvin C.D. and Kladde M.P. 2004. Effectors of lysine 4 methylation of histone $\mathrm{H} 3$ in Saccharomyces cerevisiae are negative regulators of PHO5 and GAL1-10. J. Biol. Chem. 279: 33057.

Chen H.Y., Sun J.M., Zhang Y., Davie J.R., and Meistrich M.L. 1998. Ubiquitination of histone H3 in elongating spermatids 
of rat testes. J. Biol. Chem. 273: 13165 .

Chung C.H. and Baek S.H. 1999. Deubiquitinating enzymes: Their diversity and emerging roles. Biochem. Biophys. Res. Commun. 266: 633

Clements A., Poux A.N., Lo W.S., Pillus L., Berger S.L., and Marmorstein R. 2003. Structural basis for histone and phosphohistone binding by the GCN5 histone acetyltransferase. Mol. Cell 12: 461.

Daniel J.A., Torok M.S., Sun Z.W., Schieltz D., Allis C.D., Yates J.R., III, and Grant P.A. 2004. Deubiquitination of histone $\mathrm{H} 2 \mathrm{~B}$ by a yeast acetyltransferase complex regulates transcription. J. Biol. Chem. 279: 1867.

de Napoles M., Mermoud J.E., Wakao R., Tang Y.A., Endoh M., Appanah R., Nesterova T.B., Silva J., Otte A.P., Vidal M., Koseki H., and Brockdorff N. 2004. Polycomb group proteins Ring1A/B link ubiquitylation of histone $\mathrm{H} 2 \mathrm{~A}$ to heritable gene silencing and X inactivation. Dev. Cell 7: 663.

Dover J., Schneider J., Tawiah-Boateng M.A., Wood A., Dean K., Johnston M., and Shilatifard A. 2002. Methylation of histone $\mathrm{H} 3$ by COMPASS requires ubiquitination of histone H2B by Rad6. J. Biol. Chem. 277: 28368.

Emre N.C., Ingvarsdottir K., Wyce A., Wood A., Krogan N.J., Henry K.W., Li K., Marmorstein R., Greenblatt J.R., Shilatifard A., and Berger S.L. 2005. Maintenance of low histone ubiquitylation by Ubp10 correlates with telomere proximal Sir2 association and gene silencing. Mol. Cell 17: 585.

Ezhkova E. and Tansey W.P. 2004. Proteasomal ATPases link ubiquitylation of histone H2B to methylation of histone $\mathrm{H} 3$. Mol. Cell 13: 435.

Fang J., Chen T., Chadwick B., Li E., and Zhang Y. 2004. Ring1b-mediated $\mathrm{H} 2 \mathrm{~A}$ ubiquitination associates with inactive $\mathrm{X}$ chromosomes and is involved in initiation of $\mathrm{X}$ inactivation. J. Biol. Chem. 279: 52812.

Feng Q., Wang H., Ng H.H., Erdjument-Bromage H., Tempst P., Struhl K., and Zhang Y. 2002. Methylation of H3-lysine 79 is mediated by a new family of HMTases without a SET domain. Curr. Biol. 12: 1052.

Fischle W., Wang Y., and Allis C.D. 2003. Histone and chromatin cross-talk. Curr. Opin. Cell Biol. 15: 172.

Flaus A. and Owen-Hughes T. 2004. Mechanisms for ATP-dependent chromatin remodelling: Farewell to the tuna-can octamer? Curr. Opin. Genet. Dev. 14: 165.

Game J.C., Williamson M.S., and Baccari C. 2005. X-ray survival characteristics and genetic analysis for nine Saccharomyces deletion mutants that affect radiation sensitivity. Genetics 169: 51.

Gerber M. and Shilatifard A. 2003. Transcriptional elongation by RNA polymerase II and histone methylation. J. Biol. Chem. 278: 26303.

Gonzalez F., Delahodde A., Kodadek T., and Johnston S.A. 2002. Recruitment of a 19S proteasome subcomplex to an activated promoter. Science 296: 548.

Gottschling D.E., Aparicio O.M., Billington B.L., and Zakian V.A. 1990. Position effect at S. cerevisiae telomeres: Reversible repression of Pol II transcription. Cell 63: 751.

Grant P.A., Sterner D.E., Duggan L.J., Workman J.L., and Berger S.L. 1998. The SAGA unfolds: Convergence of transcription regulators in chromatin-modifying complexes. Trends Cell Biol. 8: 193.

Grewal S.I. and Moazed D. 2003. Heterochromatin and epigenetic control of gene expression. Science 301: 798.

Grunstein M. 1997. Molecular model for telomeric heterochromatin in yeast. Curr. Opin. Cell Biol. 9: 383.

Henry K.W. and Berger S.L. 2002. Trans-tail histone modifications: Wedge or bridge? Nat. Struct. Biol. 9: 565.

Henry K.W., Wyce A., Lo W.S., Duggan L.J., Emre N.C., Kao C.F., Pillus L., Shilatifard A., Osley M.A., and Berger S.L. 2003. Transcriptional activation via sequential histone H2B ubiquitylation and deubiquitylation, mediated by SAGA-associated Ubp8. Genes Dev. 17: 2648.

Hicke L. 2001. Protein regulation by monoubiquitin. Nat. Rev. Mol. Cell Biol. 2: 195.

Hochstrasser M. 1996. Ubiquitin-dependent protein degradation. Annu. Rev. Genet. 30: 405.

Hook S.S., Orian A., Cowley S.M., and Eisenman R.N. 2002.
Histone deacetylase 6 binds polyubiquitin through its zinc finger (PAZ domain) and copurifies with deubiquitinating enzymes. Proc. Natl. Acad. Sci. 99: 13425.

Hu M., Li P., Li M., Li W., Yao T., Wu J.W., Gu W., Cohen R.E., and Shi Y. 2002. Crystal structure of a UBP-family deubiquitinating enzyme in isolation and in complex with ubiquitin aldehyde. Cell 111: 1041.

Huang H., Kahana A., Gottschling D.E., Prakash L., and Liebman S.W. 1997. The ubiquitin-conjugating enzyme Rad6 (Ubc2) is required for silencing in Saccharomyces cerevisiae. Mol. Cell. Biol. 17: 6693.

Huang Y. 2002. Transcriptional silencing in Saccharomyces cerevisiae and Schizosaccharomyces pombe. Nucleic Acids Res. 30: 1465.

Huyen Y., Zgheib O., Ditullio R.A., Jr., Gorgoulis V.G., Zacharatos P., Petty T.J., Sheston E.A., Mellert H.S., Stavridi E.S., and Halazonetis T.D. 2004. Methylated lysine 79 of histone $\mathrm{H} 3$ targets 53BP1 to DNA double-strand breaks. Nature 432: 406.

Hwang W.W., Venkatasubrahmanyam S., Ianculescu A.G., Tong A., Boone C., and Madhani H.D. 2003. A conserved RING finger protein required for histone $\mathrm{H} 2 \mathrm{~B}$ monoubiquitination and cell size control. Mol. Cell 11: 261.

Ingvarsdottir K., Krogan N.J., Emre N.C.T., Wyce A., Thompson N.J., Emili A., Hughes T.R., Greenblatt J., and Berger S.L. 2005. H2B ubiquitin protease Ubp8 and Sgf1 1 constitute a discrete functional module within the Saccharomyces cerevisiae SAGA complex. Mol. Cell. Biol. 25: 1162-1172.

Jason L.J., Finn R.M., Lindsey G., and Ausio J. 2005. Histone $\mathrm{H} 2 \mathrm{~A}$ ubiquitination does not preclude histone $\mathrm{H} 1$ binding, but it facilitates its association with the nucleosome. J. Biol. Chem. 280: 4975.

Jason L.J., Moore S.C., Lewis J.D., Lindsey G., and Ausio J. 2002. Histone ubiquitination: A tagging tail unfolds? Bioessays 24: 166.

Kao C.F., Hillyer C., Tsukuda T., Henry K., Berger S., and Osley M.A. 2004. Rad6 plays a role in transcriptional activation through ubiquitylation of histone H2B. Genes Dev. 18: 184.

Katan-Khaykovich Y. and Struhl K. 2002. Dynamics of global histone acetylation and deacetylation in vivo: Rapid restoration of normal histone acetylation status upon removal of activators and repressors. Genes Dev. 16: 743.

Kimura A., Umehara T., and Horikoshi M. 2002. Chromosomal gradient of histone acetylation established by Sas $2 p$ and Sir2p functions as a shield against gene silencing. Nat. Genet. 32: 370.

Korber P. and Horz W. 2004. SWRred not shaken; mixing the histones. Cell 117: 5.

Korber P., Luckenbach T., Blaschke D., and Horz W. 2004. Evidence for histone eviction in trans upon induction of the yeast PHO5 promoter. Mol. Cell. Biol. 24: 10965.

Krogan N.J., Dover J., Khorrami S., Greenblatt J.F., Schneider J., Johnston M., and Shilatifard A. 2002. COMPASS, a histone H3 (Lysine 4) methyltransferase required for telomeric silencing of gene expression. J. Biol. Chem. 277: 10753.

Krogan N.J., Dover J., Wood A., Schneider J., Heidt J., Boateng M.A., Dean K., Ryan O.W., Golshani A., Johnston M., Greenblatt J.F., and Shilatifard A. 2003a. The Pafl complex is required for histone $\mathrm{H} 3$ methylation by COMPASS and Dot1p: Linking transcriptional elongation to histone methylation. Mol. Cell 11: 721.

Krogan N.J., Kim M., Tong A., Golshani A., Cagney G., Canadien V., Richards D.P., Beattie B.K., Emili A., Boone C., Shilatifard A., Buratowski S., and Greenblatt J. 2003b. Methylation of histone H3 by Set2 in Saccharomyces cerevisiae is linked to transcriptional elongation by RNA polymerase II. Mol. Cell. Biol. 23: 4207.

Kurdistani S.K. and Grunstein M. 2003. Histone acetylation and deacetylation in yeast. Nat. Rev. Mol. Cell Biol. 4: 276.

Ladurner A.G., Inouye C., Jain R., and Tjian R. 2003. Bromodomains mediate an acetyl-histone encoded antisilencing function at heterochromatin boundaries. Mol. Cell 11: 365.

Laity J.H., Lee B.M., and Wright P.E. 2001. Zinc finger proteins: New insights into structural and functional diversity. 
Curr. Opin. Struct. Biol. 11: 39.

Lee K.K., Florens L., Swansen S.K., Washburn M.P., and Workman J.L. 2005. The deubiquitylation activity of Ubp8 is dependent upon Sgf11 and its association with the SAGA complex. Mol. Cell. Biol. 25: 1173-1182.

Lee K.K., Prochasson P., Florens L., Swanson S.K., Washburn M.P., and Workman J.L. 2004. Proteomic analysis of chromatin-modifying complexes in Saccharomyces cerevisiae identifies novel subunits. Biochem. Soc. Trans. 32: 899.

Lo W.S., Duggan L., Emre N.C.T., Belotserkovskya R., Lane W.S., Shiekhattar R., and Berger S.L. 2001. Snf1-A histone kinase that works in concert with the histone acetyltransferase Gen5 to regulate transcription. Science 293: 1142 .

Luger K. 2003. Structure and dynamic behavior of nucleosomes. Curr. Opin. Genet. Dev. 13: 127.

Matunis M.J. 2002. On the road to repair: PCNA encounters SUMO and ubiquitin modifications. Mol. Cell 10: 441.

Meneghini M.D., Wu M., and Madhani H.D. 2003. Conserved histone variant H2A.Z protects euchromatin from the ectopic spread of silent heterochromatin. Cell 112: 725.

Michael D. and Oren M. 2003. The p53-Mdm2 module and the ubiquitin system. Semin. Cancer Biol. 13: 49.

Minsky N. and Oren M. 2004. The RING domain of Mdm2 mediates histone ubiquitylation and transcriptional repression. Mol. Cell 16: 631.

Moazed D. and Johnson D. 1996. A deubiquitinating enzyme interacts with SIR4 and regulates silencing in S. cerevisiae. Cell 86: 667.

Moazed D., Rudner A.D., Huang J., Hoppe G.J., and Tanny J.C. 2004. A model for step-wise assembly of heterochromatin in yeast. Novartis Found. Symp. 259: 48.

Moore S.C., Jason L., and Ausio J. 2002. The elusive structural role of ubiquitinated histones. Biochem. Cell Biol. 80: 311.

Muratani M. and Tansey W.P. 2003. How the ubiquitin-proteasome system controls transcription. Nat. Rev. Mol. Cell Biol. 4: 192.

Nathan D., Sterner D.E., and Berger S.L. 2003. Histone modifications: Now summoning sumoylation. Proc. Natl. Acad. Sci. 100: 13118.

$\mathrm{Ng}$ H.H., Dole S., and Struhl K. 2003a. The Rtfl component of the Paf1 transcriptional elongation complex is required for ubiquitination of histone H2B. J. Biol. Chem. 278: 33625 .

Ng H.H., Robert F., Young R.A., and Struhl K. 2003b. Targeted recruitment of Set1 histone methylase by elongating Pol II provides a localized mark and memory of recent transcriptional activity. Mol. Cell 11: 709.

Ng H.H., Xu R.M., Zhang Y., and Struhl K. 2002a. Ubiquitination of histone H2B by Rad6 is required for efficient Dot1mediated methylation of histone H3 lysine 79. J. Biol. Chem. 277: 34655.

Ng H.H., Ciccone D.N., Morshead K.B., Oettinger M.A., and Struhl K. 2003c. Lysine-79 of histone H3 is hypomethylated at silenced loci in yeast and mammalian cells: A potential mechanism for position-effect variegation. Proc. Natl. Acad. Sci. 100: 1820 .

Ng H.H., Feng Q., Wang H., Erdjument-Bromage H., Tempst P., Zhang Y., and Struhl K. 2002b. Lysine methylation within the globular domain of histone H3 by Dot1 is important for telomeric silencing and Sir protein association. Genes Dev. 16: 1518.

Nislow C., Ray E., and Pillus L. 1997. SET1, a yeast member of the trithorax family, functions in transcriptional silencing and diverse cellular processes. Mol. Biol. Cell 8: 2421.

Noma K. and Grewal S.I. 2002. Histone H3 lysine 4 methylation is mediated by Set 1 and promotes maintenance of active chromatin states in fission yeast. Proc. Natl. Acad. Sci. (suppl. 4) 99: 16438 .

Osley M.A. 2004. H2B ubiquitylation: The end is in sight. Biochim. Biophys. Acta 1677: 74.

Pham A.D. and Sauer F. 2000. Ubiquitin-activating/conjugating activity of TAFII250, a mediator of activation of gene expression in Drosophila. Science 289: 2357.

Powell D.W., Weaver C.M., Jennings J.L., McAfee K.J., He Y., Weil P.A., and Link A.J. 2004. Cluster analysis of mass spec- trometry data reveals a novel component of SAGA. Mol. Cell. Biol. 24: 7249.

Robzyk K., Recht J., and Osley M.A. 2000. Rad6-dependent ubiquitination of histone H2B in yeast. Science 287: 501.

Roguev A., Schaft D., Shevchenko A., Aasland R., Shevchenko A., and Stewart A.F. 2003. High conservation of the Set1/Rad6 axis of histone 3 lysine 4 methylation in budding and fission yeasts. J. Biol. Chem. 278: 8487.

Rusche L.N., Kirchmaier A.L., and Rine J. 2003. The establishment, inheritance, and function of silenced chromatin in Saccharomyces cerevisiae. Annu. Rev. Biochem. 72: 481.

Sanders S.L., Jennings J., Canutescu A., Link A.J., and Weil P.A. 2002. Proteomics of the eukaryotic transcription machinery: Identification of proteins associated with components of yeast TFIID by multidimensional mass spectrometry. Mol. Cell. Biol. 22: 4723.

San-Segundo P.A. and Roeder G.S. 2000. Role for the silencing protein Dot1 in meiotic checkpoint control. Mol. Biol. Cell 11: 3601 .

Santos-Rosa H., Bannister A.J., Dehe P.M., Geli V., and Kouzarides T. 2004. Methylation of H3 lysine 4 at euchromatin promotes Sir3p association with heterochromatin. $J$. Biol. Chem. 279: 47506.

Santos-Rosa H., Schneider R., Bannister A.J., Sherriff J., Bernstein B.E., Emre N.C.T., Schreiber S.L., Mellor J., and Kouzarides T. 2002. Active genes are tri-methylated at K4 of histone H3. Nature 419: 407.

Schwabish M.A. and Struhl K. 2004. Evidence for eviction and rapid deposition of histones upon transcriptional elongation by RNA polymerase II. Mol. Cell. Biol. 24: 10111.

Seigneurin-Berny D., Verdel A., Curtet S., Lemercier C., Garin J., Rousseaux S., and Khochbin S. 2001. Identification of components of the murine histone deacetylase 6 complex: Link between acetylation and ubiquitination signaling pathways. Mol. Cell. Biol. 21: 8035.

Shilatifard A. 2004. Transcriptional elongation control by RNA polymerase II: A new frontier. Biochim. Biophys. Acta 1677: 79.

Singer M.S., Kahana A., Wolf A.J., Meisinger L.L., Peterson S.E., Goggin C., Mahowald M., and Gottschling D.E. 1998. Identification of high-copy disruptors of telomeric silencing in Saccharomyces cerevisiae. Genetics 150: 613.

Soboleva T.A. and Baker R.T. 2004. Deubiquitinating enzymes: Their functions and substrate specificity. Curr. Protein Pept. Sci. 5: 191.

Sollier J., Lin W., Soustelle C., Suhre K., Nicolas A., Geli V., and De La Roche Saint-Andre C. 2004. Set1 is required for meiotic S-phase onset, double-strand break formation and middle gene expression. EMBO J. 23: 1957.

Sterner D.E., Grant P.A., Roberts S.M., Duggan L.J., Belotserkovskaya R., Pacella L.A., Winston F., Workman J.L., and Berger S.L. 1999. Functional organization of the yeast SAGA complex: Distinct components involved in structural integrity, nucleosome acetylation, and TATA-binding protein interaction. Mol. Cell. Biol. 19: 86.

Suka N., Luo K., and Grunstein M. 2002. Sir2p and Sas2p opposingly regulate acetylation of yeast histone $\mathrm{H} 4$ lysine 16 and spreading of heterochromatin. Nat. Genet. 32: 378 .

Sun Z.W. and Allis C.D. 2002. Ubiquitination of histone H2B regulates $\mathrm{H} 3$ methylation and gene silencing in yeast. Nature 418: 104 .

Turner S.D., Ricci A.R., Petropoulos H., Genereaux J., Skerjanc I.S., and Brandl C.J. 2002. The E2 ubiquitin conjugase Rad6 is required for the $\mathrm{ArgR} / \mathrm{Mcm} 1$ repression of $\mathrm{ARG} 1$ transcription. Mol. Cell. Biol. 22: 4011.

van Leeuwen F. and Gottschling D.E. 2002. Genome-wide histone modifications: Gaining specificity by preventing promiscuity. Curr. Opin. Cell Biol. 14: 756.

van Leeuwen F., Gafken P.R., and Gottschling D.E. 2002. Dot1p modulates silencing in yeast by methylation of the nucleosome core. Cell 109: 745.

Wang H., Wang L., Erdjument-Bromage H., Vidal M., Tempst P., Jones R.S., and Zhang Y. 2004. Role of histone H2A ubiquitination in Polycomb silencing. Nature 431: 873. 
Wilkinson K.D. 1997. Regulation of ubiquitin-dependent processes by deubiquitinating enzymes. FASEB J. 11: 1245.

. 2000. Ubiquitination and deubiquitination: Targeting of proteins for degradation by the proteasome. Semin. Cell Dev. Biol. 11: 141.

Wood A., Schneider J., Dover J., Johnston M., and Shilatifard A. 2003a. The Pafl complex is essential for histone monoubiquitination by the Rad6-Bre1 complex, which signals for histone methylation by COMPASS and Dot1p. J. Biol. Chem. 278: 34739 .

Wood A., Krogan N.J., Dover J., Schneider J., Heidt J., Boateng M.A., Dean K., Golshani A., Zhang Y., Greenblatt J.F., Johnston M., and Shilatifard A. 2003b. Bre1, an E3 ubiquitin ligase required for recruitment and substrate selection of Rad6 at a promoter. Mol. Cell 11: 267.

Wyce A., Henry K.W., and Berger S.L. 2004. H2B ubiquitylation and de-ubiquitylation in gene activation. Novartis Found. Symp. 259: 63.

Xiao T., Hall H., Kizer K.O., Shibata Y., Hall M.C., Borchers C.H., and Strahl B.D. 2003. Phosphorylation of RNA polymerase II CTD regulates H3 methylation in yeast. Genes Dev. 17: 654.

Yamashita K., Shinohara M., and Shinohara A. 2004. Rad6Bre1-mediated histone $\mathrm{H} 2 \mathrm{~B}$ ubiquitylation modulates the formation of double-strand breaks during meiosis. Proc. Natl. Acad. Sci. 101: 11380.

Zhang Y. 2003. Transcriptional regulation by histone ubiquitination and deubiquitination. Genes Dev. 17: 2733. 


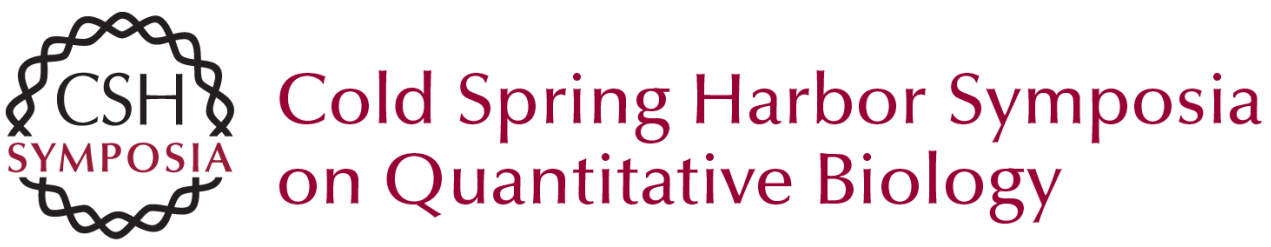

\section{Histone H2B Ubiquitylation and Deubiquitylation in Genomic Regulation}

N.C.T. EMRE and S.L. BERGER

Cold Spring Harb Symp Quant Biol 2004 69: 289-300

Access the most recent version at doi:10.1101/sqb.2004.69.289

References This article cites 104 articles, 47 of which can be accessed free at: http://symposium.cshlp.org/content/69/289.full.html\#ref-list-1

License

Email Alerting Receive free email alerts when new articles cite this article - sign up in Service the box at the top right corner of the article or click here. 